\title{
Passive Lossless Snubbers Using the Coupled Inductor Method for the Soft Switching Capability of Boost PFC Rectifiers
}

\author{
Ho-Sung Kim ${ }^{*}$, Ju-Won Baek ${ }^{*}$, Myung-Hyo Ryu*, Jong-Hyun Kim${ }^{*}$, and Jee-Hoon Jung ${ }^{\dagger}$ \\ * Power Conversion and Control Research Center, Korea Electrotechnology Research Institute, Changwon, Korea \\ ${ }^{\dagger}$ School of Electrical and Computer Engineering, Ulsan National Institute of Science and Technology,Ulsan, Korea
}

\begin{abstract}
In order to minimize switching losses for high power applications, a boost PFC rectifier with a novel passive lossless snubber circuit is proposed. The proposed lossless snubber is composed of coupled inductors merged into a boost inductor. This method compared with conventional methods does not need additional inductor cores and it reduces extra costs to implement a soft switching circuit. Especially, the proposed circuit can reduce the reverse recovery current of output diode rectifiers due to the coupling effect of the inductor. During turn-on and turn-off operating modes, the proposed PFC converter operates under soft switching conditions with high power conversion efficiency. In addition, the performance improvement and analysis of the operating effects of the coupled inductors were also presented and verified with a $3.3 \mathrm{~kW}$ prototype rectifier.
\end{abstract}

Key words: Boost PFC converter, Coupled inductor, Lossless snubber, Soft switching

\section{INTRODUCTION}

A boost converter operating in the continuous conduction mode (CCM) is the most popular topology for implementing power factor correction (PFC) in high power applications [1]-[5]. However, the conventional operation of the CCM boost converter causes high reverse recovery losses of the output diodes as well as electromagnetic interference (EMI) noises. The switching losses and the EMI noises of the CCM boost rectifier are mainly generated during the switching transient of the main power switches. The reverse recovery current of the boost diode during the turn-on process induces a high surge current which flows through the main switch. In addition, a rapid increment of the drain-source voltage during the turn-off switching transient also results in EMI noise and turn-off switching losses. In order to increase the rated power of the $\mathrm{CCM}$ boost converter with a high power conversion efficiency,

Manuscript received Mar. 27, 2014; accepted Aug. 5, 2014

Recommended for publication by Associate Editor Yan Xing.

${ }^{\dagger}$ Corresponding Author: jhjung@unist.ac.kr

Tel: $+82-52-217-2140$, Fax: +82-52-217-2109, School of Electrical and Computer Engineering, UNIST

* Power Conversion and Control Research Center, Korea Electrotechnology Research Institute, Korea these phenomena should be eliminated.

Many previous studies have improved the performance of high power CCM boost converters. These studies have focused on reducing the effects of the reverse-recovery characteristic of the boost converter and increasing the power conversion efficiency. An alternative method to minimize these drawbacks is the use of a silicon carbide ( $\mathrm{SiC}$ ) diode [6]-[9] or a soft switching circuit instead of the conventional diode rectifiers. The $\mathrm{SiC}$ diode can reduce the power losses caused by the reverse recovery current. It has the simplest structure when compared with other methods. However, this method still has a hard switching problem of the main switch. In addition, the SiC diode has a higher forward voltage drop than that of a conventional fast recovery diode (FRD). If the output power increases, the power loss of the $\mathrm{SiC}$ diode is also increased. Furthermore, a $\mathrm{SiC}$ diode with a high rated current is more expensive than other devices. For this reason, boost rectifiers using $\mathrm{SiC}$ diodes are not suitable for high power applications.

The soft switching circuit for a CCM boost rectifier can reduce the reverse recovery by reducing the falling rate of the output diode's turn-off current. Various soft switching techniques using active and passive snubber circuits have been proposed [10]-[21]. The active snubber circuits can achieve 


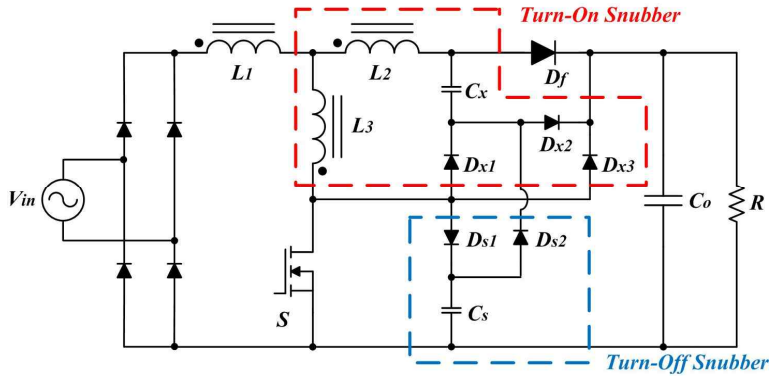

Fig. 1. Proposed PFC boost converter with lossless snubber.

zero voltage switching (ZVS) and zero current switching (ZCS) for the main switch. However, they require an additional control circuit to drive the auxiliary switch which operates under hard switching conditions. Moreover, in order to increase the power conversion efficiency for high power applications, expensive components with high power ratings are required. Therefore, the cost of the circuit is increased and the reliability is deceased by using active snubber circuits.

Generally, passive lossless snubbers are as effective as active snubbers without any additional auxiliary switches or control circuits [14]-[21]. Low cost, high performance, and high reliability are the advantages of passive lossless snubbers. A simple passive snubber circuit using a flying-capacitor has been proposed for a basic PFC topology [14], [15], a three-level PFC topology [16], and a bridgeless PFC topology [17]. These methods have basic circuit structures using snubber capacitors, inductors, and diodes. The general form of turn-on passive snubber circuits using energy recovery capability is an inductor series connected to the main switch. Therefore, these circuits require additional inductor components. In addition, these circuits cannot operate as a turn-off snubber. The turn-off snubber of the main switch is composed of resistor capacitor diode (RCD) snubbers so as to confine the rise of the switch voltage [18]. However, the power loss of the snubber resistor reduces the overall power conversion efficiency. A passive snubber circuit using saturable inductors is used to reduce the reverse recovery current of the output diodes [19], [20]. However, this causes extra voltage stress on the main switches and increases costs due to the additional inductors. A snubber circuit with saturable inductors is adapted to reduce the reverse recovery current of the output diodes [21]. It does not introduce extra voltage or current stress on the main switch. However, it needs nine additional passive components with three additional snubber inductors, which has the demerits of a large circuit size and extra cost.

In this paper, a novel passive lossless snubber circuit is proposed to improve the power conversion efficiency of a CCM boost PFC rectifier for high power applications. In order to use the proposed turn-on snubber circuit, the turn-on current of the main switch resulting from the reverse recovery current of the output diode is limited. In addition, the turn-off lossless snubber can reduce the voltage spike of the main switch during turn-off transitions. The proposed snubber circuit consists of nine additional components composed of six components for a turn-on snubber, and three components for a turn-off snubber. The proposed turn-on snubber consists of coupled inductors merged into the boost inductor. However, the additional cores of the snubber inductor are not required because three inductors are coupled in a single core. Actually, seven additional components are used for the proposed lossless snubber circuit. Therefore, it can reduce both the circuit size and the extra cost. Even though it requires a relatively large number of passive components when compared with the $\mathrm{SiC}$ diode-based PFC, the proposed technique in high power rectifier applications is a good solution for reducing reverse recovery problems. The performance of the proposed lossless snubber circuit will be experimentally verified using a $3.3 \mathrm{~kW}$ prototype PFC rectifier.

\section{Proposed PASSIVE LOSSLESS SNUBBER}

\section{A. Circuit Diagram}

Fig. 1 shows a schematic of a PFC boost rectifier with the proposed lossless snubber circuit. The conventional boost PFC converter contains a boost inductor $L_{l}$, a main switch $S$, an output diode $D_{f}$, and an output capacitor $C_{o}$. The proposed turn-on passive snubber consists of two coupled inductors $L_{2}$ and $L_{3}$, three auxiliary diodes $D_{x 1}, D_{x 2}$, and $D_{x 3}$, and an additional capacitor $C_{x}$. The inductors $L_{1}, L_{2}$, and $L_{3}$ are coupled using a single core structure. The turn ratio of the coupled inductors is $n: 1: 1 \quad(n>>1)$. The turn-off snubber circuit consists of a capacitor in parallel with the main switch $C_{s}$ and two diodes $D_{s 1}$ and $D_{s 2}$. A PFC circuit using the proposed snubber method has been presented in international conference [22]. However, this paper did not suggest an entire power stage design. In addition, the effect of the proposed coupled inductor was not considered. In this paper, the performance improvement and analysis of the operating effects of the coupled inductors will be presented. The detailed circuit operation of the proposed PFC rectifier will be discussed in the next section.

\section{B. Operating Principles}

To analyze the steady state operation of the proposed PFC converter, following assumptions are made during one switching period:

1) The output capacitor $C_{o}$ is large enough to assure that the output voltage $V_{o}$ is constant and ripple-free.

2) The input voltage $V_{\text {in }}$ is constant in one switching period.

3) All semiconductor devices are assumed to be ideal, except for the output diode $D_{f}$.

4) The inductance of $L_{l}$ is much greater than the inductance of $L_{2}$ and $L_{3}$.

5) The equivalent coupled inductance $L_{e q}$ assumes that the coupling effect between $L_{2}$ and $L_{3}$ is perfectly coupled. 


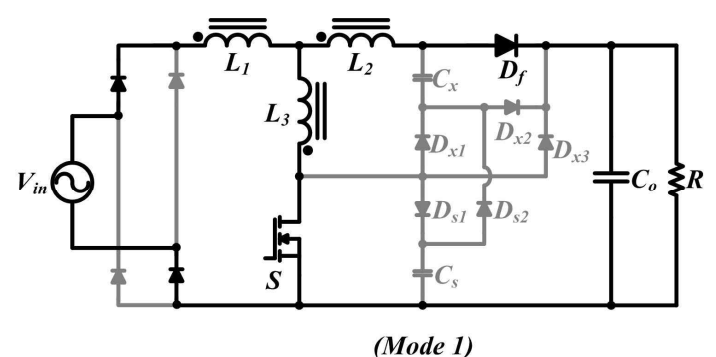

(a)

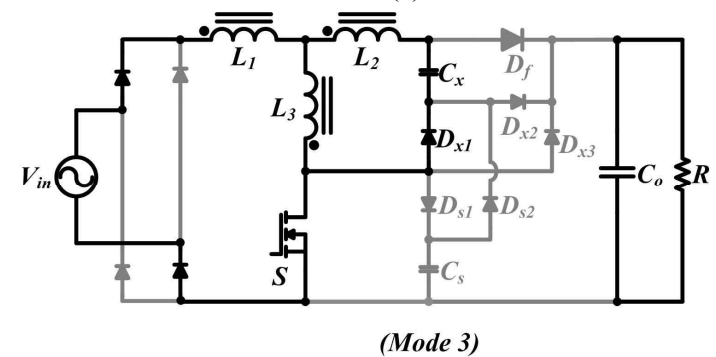

(b)

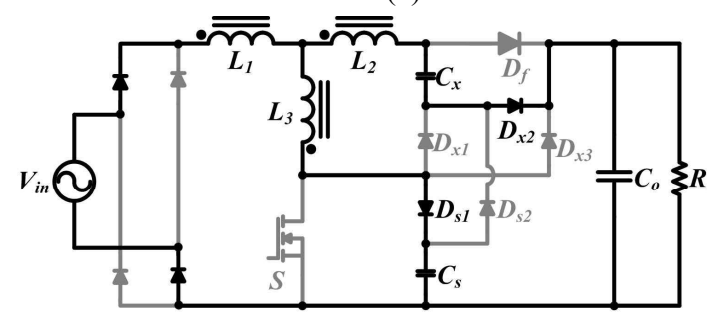

(Mode 5)

(e)

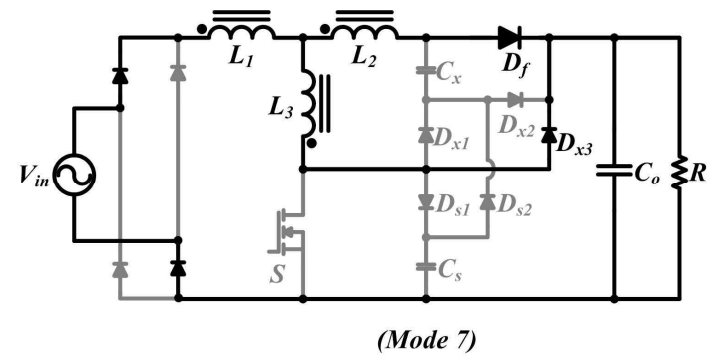

(g)

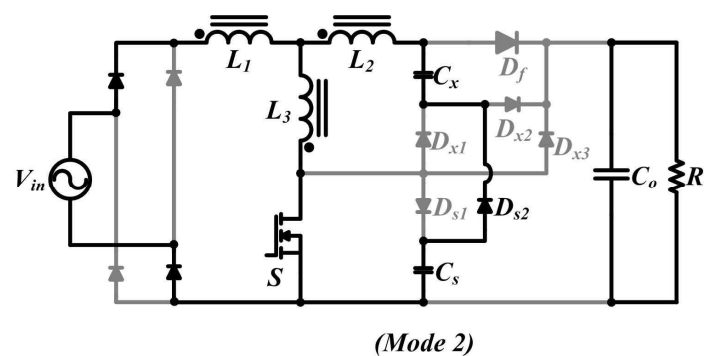

(b)

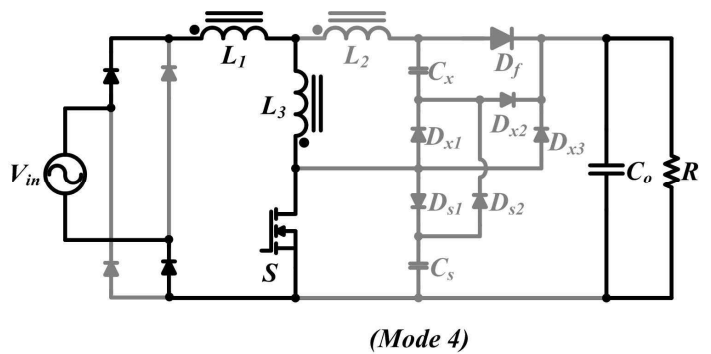

(d)

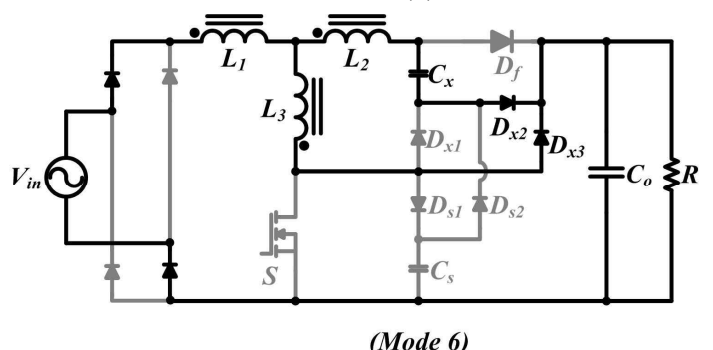

(f)

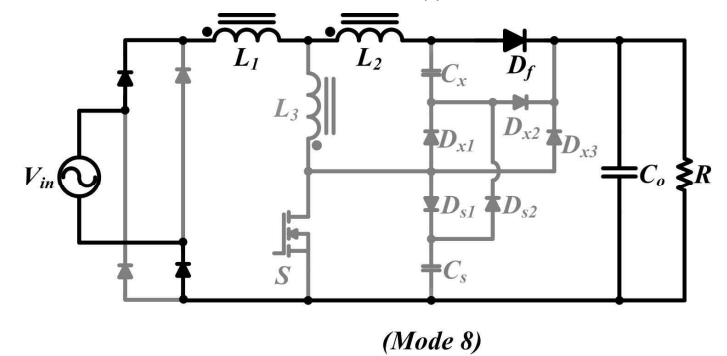

(h)

Fig. 2. Operating mode of the proposed rectifier: (a) Mode 1, (b) Mode 2, (c) Mode 3, (d) Mode 4, (e) Mode 5, (f) Mode 6, (g) Mode 7, (h) Mode 8.

There are eight operating modes in a single switching cycle. The circuit operations in the positive half period of the input voltage are shown in Fig. 2. The dark lines denote the conducting paths for each state. The theoretical waveforms of the proposed rectifier are given in Fig 3.

Mode 1 [ $\boldsymbol{t}_{\boldsymbol{0}}-\boldsymbol{t}_{1}$ ]: At $t_{0}, S$ turns on. When $S$ turns on, $D_{f}$ is not immediately turned off because of its reverse recovery process. Snubber inductors $L_{2}$ and $L_{3}$ limit the rising rate of the switch current. The inductor currents are shown as follows:

$$
\begin{gathered}
I_{L 1}(t)=I_{L 1}\left(t_{0}\right)+\frac{(1-D) V_{\text {out }}}{L_{1}+L_{3}}\left(t-t_{0}\right) \\
I_{L 1}(t)=I_{L 2}\left(t_{0}\right)-\frac{V_{\text {out }}}{L_{e q}}\left(t-t_{0}\right)
\end{gathered}
$$

$$
I_{L 3}(t)=\frac{(1-D) V_{\text {out }}}{L_{1}+L_{3}}\left(t-t_{0}\right)+\frac{V_{\text {out }}}{L_{2}+L_{3}}\left(t-t_{0}\right)
$$

where the voltage across $L_{2}$ and $L_{3}$ is $-V_{L 2}=V_{L 3}=\frac{1}{2} V_{\text {out }}$, the switch current is $I_{s}=I_{L 3}=I_{L 1}-I_{L 2}$, and $I_{L 1}\left(t_{0}\right)-I_{L 2}\left(t_{0}\right)=0$. The equivalent coupled inductance $L_{e q}$ will be defined in Section III.

At $t_{1}, I_{L 3}$ reaches $I_{i n}$. Thus, the duration of Mode 1 can be calculated in (4).

$$
t_{1}-t_{0}=\frac{L_{3} I_{\text {in }}}{V_{\text {out }}}
$$

Mode $2\left[\boldsymbol{t}_{1}-\boldsymbol{t}_{2}\right]$ : The reverse recovery phenomenon of $D_{f}$ is finished at $t_{l}$. Since $D_{f}$ is turned off, $I_{L 2}$ charges $C_{x}$ through $L_{3}$, 
$C_{s}$, and $D_{s 2}$. Each inductor current and the voltage of the snubber capacitor in Mode 2 can be derived as follows:

$$
\begin{gathered}
I_{L 1}(t)=I_{L 1}\left(t_{1}\right)-\frac{L_{2}}{L_{1}} I_{L 2}(t) \\
I_{L 2}(t)=\frac{V_{\text {out }}}{Z_{1}} \sin \omega_{1}\left(t-t_{1}\right)-i_{r 1} \cos \omega_{1}\left(t-t_{1}\right) \\
I_{L 3}(t)=I_{L 1}\left(t_{1}\right)-\left(1+\frac{L_{2}}{L_{1}}\right) I_{L 2}(t) \\
V_{C x}(t)=\frac{C_{s}}{C_{x}+C_{s}} V_{\text {out }} \cos \omega_{1}\left(t-t_{1}\right)+\frac{i_{r 1}}{C_{s} \omega_{1}} \sin \omega_{1}\left(t-t_{1}\right)
\end{gathered}
$$

where $i_{r 1}=-I_{L 2}\left(t_{0}\right)+\frac{V_{\text {out }}}{L_{\text {eq }}}\left(t_{1}-t_{0}\right), \quad \omega_{1}=\sqrt{\frac{C_{x}+C_{s}}{L_{e q}\left(C_{x} C_{s}\right)}}, \quad$ and $Z_{1}=\sqrt{\frac{L_{e q}\left(C_{x}+C_{s}\right)}{C_{x} C_{s}}}$. This mode ends at $t_{2}$ when $V_{C s}\left(t_{2}\right)=0$.

Since the turn ratio of the coupled inductors $L_{2}$ and $L_{3}$ is $1: 1$, the voltage across the snubber capacitor at $t_{2}$ is $V_{C x}\left(t_{2}\right)=$ $V_{L 2}\left(t_{2}\right)-V_{L 3}\left(t_{2}\right)=2 V_{L 2}\left(t_{2}\right)$. The voltage across the snubber inductor $L_{2}$ at $t_{2}$ can be calculated in (9).

$$
V_{L 2}\left(t_{2}\right) \simeq \frac{1}{2} V_{\text {out }} \cos \omega_{1}\left(t_{2}-t_{1}\right)+L_{2} \omega_{1} i_{r 1} \sin \omega_{1}\left(t_{2}-t_{1}\right)
$$

The capacitance of $C_{x}$ should be much larger than the capacitance of $C_{s}$ for the soft switching of the main switch $S$. Thus, using (8) and (9), the duration of Mode 2 can be approximated in (10).

$$
t_{2}-t_{1} \simeq \frac{1}{\omega_{1}} \tan ^{-1}\left[\frac{C_{s} \omega_{1} V_{\text {out }}}{i_{r 1}\left(1-2 L_{2} C_{x} \omega_{1}^{2}\right)}\right]
$$

Mode 3 [ $\left.\boldsymbol{t}_{2}-\boldsymbol{t}_{3}\right]$ : At $t_{2}, D_{s 2}$ is turned off, and $D_{x l}$ is turned on. During this period, the energy stored in $L_{2}$ and $L_{3}$ is transferred to $C_{x}$ through the resonant path $L_{2}-L_{3}-D_{x l}-C_{x}$. The boost inductor current $I_{L 1}$, the resonant current $I_{L 2}$, and the voltage across $C_{x}$ are shown as follows:

$$
\begin{gathered}
I_{L 1}(t)=I_{L 1}\left(t_{2}\right)+\frac{1}{L_{1}} \cdot \frac{n(1-D)}{n-1} V_{\text {out }}\left(t-t_{2}\right) \\
I_{L 2}(t)=\frac{(1-D) V_{\text {out }}}{2} \sin \omega_{2}\left(t-t_{2}\right)-i_{r 2} \cos \omega_{2}\left(t-t_{2}\right) \\
V_{C x}(t)=V_{C x}\left(t_{2}\right)+\frac{(1-D) V_{\text {out }}}{2} \cos \omega_{2}\left(t-t_{2}\right)+\frac{i_{r 2}}{Z_{2}} \sin \omega_{2}\left(t-t_{2}\right)
\end{gathered}
$$

where $i_{r 2}=\frac{V_{\text {out }}}{Z_{1}} \sin \omega_{1}\left(t_{2}-t_{1}\right)-i_{r 1} \cos \omega_{1}\left(t_{2}-t_{1}\right), \quad \omega_{2}=\frac{1}{\sqrt{L_{e q} C_{x}}}$, and $Z_{2}=\sqrt{\frac{L_{e q}}{C_{x}}}$. Since the coupling between inductors $L_{l}$ and $L_{3}$ has a turns ratio of $n: 1$, the voltage of the boost inductor, $V_{L 1}$, is $V_{L 1}\left(t_{3}\right)=V_{\text {in }}-V_{L 3}\left(t_{3}\right)=\frac{n(1-D)}{n-1} V_{\text {out }}$.

At $t_{3}, I_{L 2}$ is decreased to zero. Therefore, by using (12), the duration of Mode 3 is can be derived in (14).

$$
t_{3}-t_{2}=\frac{1}{\omega_{2}} \tan ^{-1}\left[\frac{2 Z_{2} i_{r 2}}{(1-D) V_{\text {out }}}\right]
$$

Mode $4\left[\boldsymbol{t}_{3}-\boldsymbol{t}_{4}\right]$ : At $t_{3}$, switch $S$ is still turned on. During

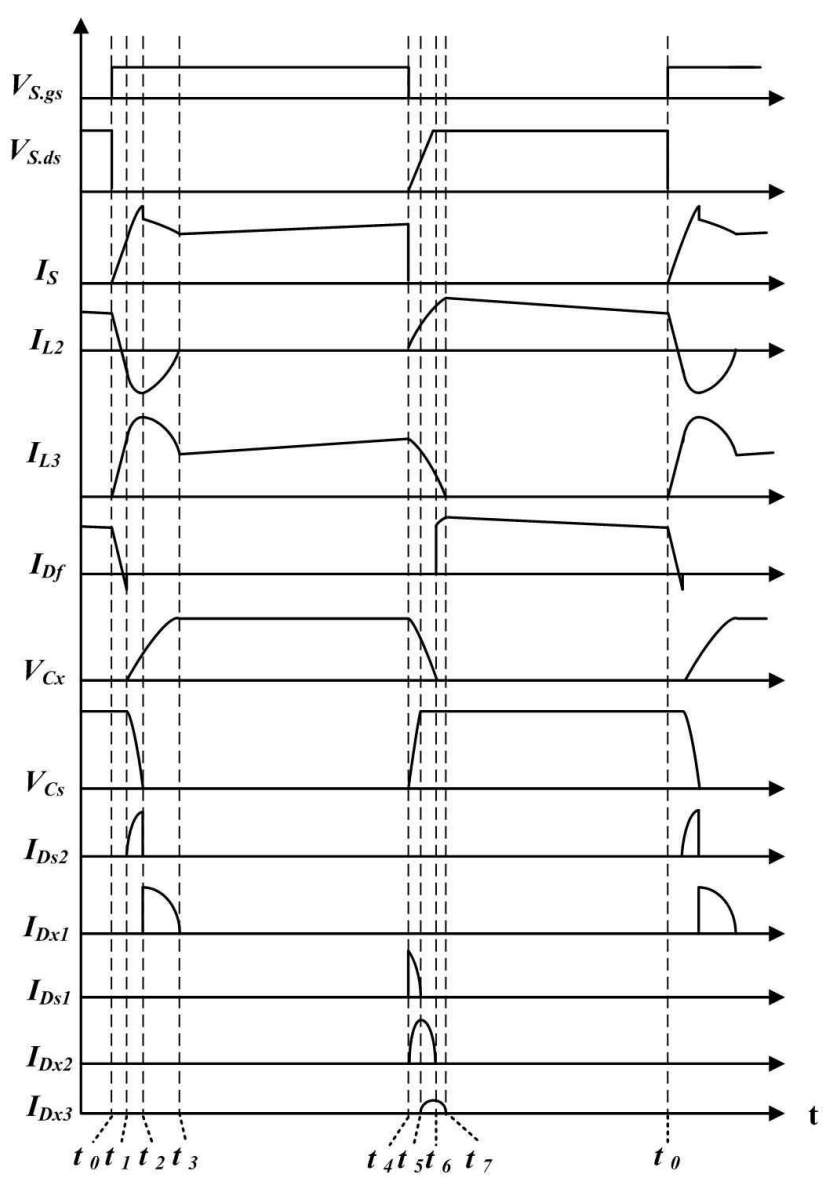

Fig. 3. Theoretical waveforms of the converter.

this period, $L_{3}$ becomes short-circuit. Thus, the switch current $I_{s}$ equals $I_{L I}$. The duration of Mode 4 defines the duty cycle of the main switch. This mode ends when $S$ is turned off softly at $t_{4}$.

Mode 5 [ $\boldsymbol{t}_{4}-\boldsymbol{t}_{5}$ ]: At $t_{4}, I_{L 3}$ flows through $D_{s l}$ and charges $C_{S}$. The main switch $S$ is softly turned off. The resonant current $I_{L 3}$ and the snubber voltage $V_{C s}$ are shown as follows:

$$
\begin{array}{r}
I_{L 3}(t)=\left[i_{r 3}-\frac{(1-D) V_{\text {out }}}{L_{1}+L_{3}}\right] \cos \omega_{3}\left(t-t_{4}\right) \\
V_{C S}(t)=\left[i_{r 3} Z_{3}+\omega_{3}(1-D) V_{\text {out }}\right] \sin \omega_{3}\left(t-t_{4}\right)
\end{array}
$$

where

$$
i_{r 3} \simeq \frac{(1-D) V_{\text {out }}}{L_{1}}\left(t_{4}-t_{3}\right) \quad, \quad \omega_{3}=\frac{1}{\sqrt{\left(L_{1}+L_{3}\right) C_{s}}},
$$

$Z_{3}=\sqrt{\frac{L_{1}+L_{3}}{C_{s}}} \cdot$

At the same time, the energy stored in $C_{x}$ begins to discharge through $D_{x 2} . I_{L 2}$ and $V_{C x}$ are shown as follows:

$$
\begin{gathered}
I_{L 2}(t)=\frac{D V_{\text {out }}}{L_{1}+L_{2}} \cos \omega_{4}\left(t-t_{4}\right)-v_{r 1} Z_{4} \sin \omega_{4}\left(t-t_{4}\right) \\
V_{C x}(t)=v_{r 1}-\omega_{4} D V_{\text {out }} \sin \omega_{4}\left(t-t_{4}\right)-C_{x} v_{r 1} Z_{4} \cos \omega_{4}\left(t-t_{4}\right)
\end{gathered}
$$

where $\quad v_{r 1}=V_{C x}\left(t_{2}\right)+\frac{2}{n} V_{i n} \cos \omega_{2}\left(t_{3}-t_{2}\right)+\frac{i_{r 2}}{Z_{2}} \sin \omega_{2}\left(t_{3}-t_{2}\right)$

$\omega_{4}=\frac{1}{\sqrt{\left(L_{1}+L_{2}\right) C_{x}}}$, and $Z_{4}=\sqrt{\frac{L_{1}+L_{2}}{C_{x}}}$. 


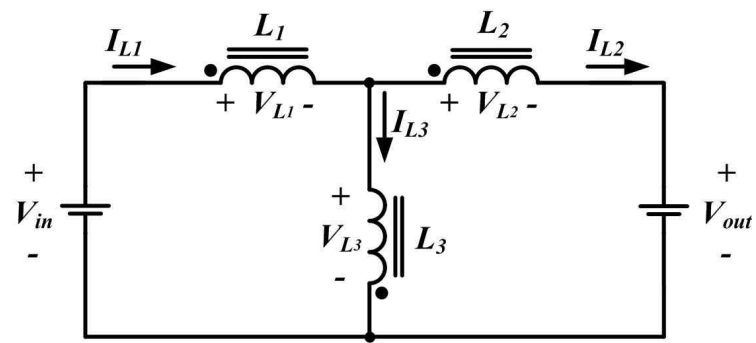

(a)

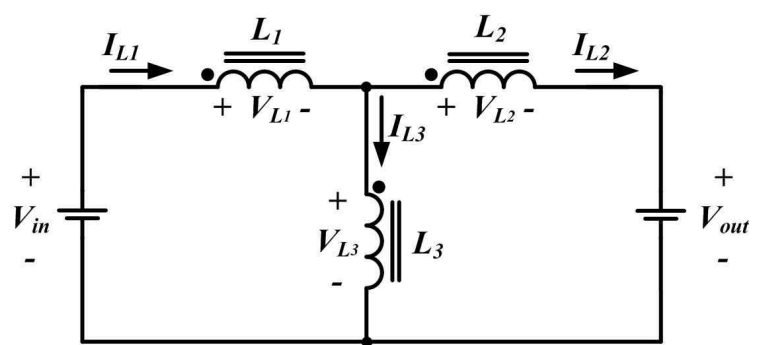

(b)

Fig. 4. Equivalent circuits of two coupled inductors in Mode 1. (a) inverse coupling, (b) direct coupling.

At $t_{5}$, the energy stored in $C_{s}$ is fully charged and the voltage across $C_{s}$ is $V_{C s} \simeq V_{\text {out }}$. Therefore, by using (16) the duration of Mode 5 can be derived in (19).

$$
t_{5}-t_{4} \simeq \frac{1}{\omega_{3}} \sin ^{-1}\left[\frac{V_{\text {out }}}{i_{r_{3}} Z_{3}+\omega_{3} V_{\text {out }}(1-D)}\right]
$$

Mode $6\left[\boldsymbol{t}_{5}-\boldsymbol{t}_{6}\right]$ : At $t_{5}, C_{x}$ is still discharged through $D_{x 2}$ and $V_{C x}$ has the same value as (18). The stored energy in $L_{3}$ is transferred to the output capacitor through $D_{x 3}$. $I_{L 3}$ can be expressed as:

$$
I_{L 3}(t) \simeq i_{r 4}-\frac{1}{n} \cdot \frac{(1-D) V_{\text {out }}}{L_{3}}\left(t-t_{5}\right)
$$

where $i_{r 4}$ is the same as $I_{L 3}\left(\mathrm{t}_{5}\right)$ in Mode 5. $V_{C x}$ is discharged to zero at $t_{6}$.

Mode 7 [ $\left.\boldsymbol{t}_{6}-\boldsymbol{t}_{7}\right]$ : At $t_{6}$, the output diode $D_{f}$ is turned on. The energy in the input voltage source and boost inductor $L_{l}$ starts to flow to the output through $D_{f}$. During this period, the energy remained in $L_{3}$ is fully discharged. $I_{L 3}$ is the same as (20). The duration of this mode can be calculated in (21).

$$
t_{7}-t_{6}=\frac{I_{L 3}\left(t_{6}\right)}{\frac{1}{n} \cdot \frac{(1-D) V_{\text {out }}}{L_{3}}}
$$

Mode $8\left[\boldsymbol{t}_{7}-\boldsymbol{t}_{\boldsymbol{g}}\right]$ : At $t_{7}, D_{f}$ is still turned on and snubber diode $D_{s 3}$ is turned off. During this period, snubber inductor $L_{2}$ becomes short-circuit. This mode ends when the main switch $S$ is turned on again and the operation proceeds to Mode 1 .

\section{ANALYSIS AND DESIGN GUIDES OF THE PROPOSED LOSSLESS SNUBBER CIRCUIT}

\section{A. The Coupled Inductor}

As shown in Fig. 1, two snubber inductors of the proposed lossless snubber are built on the same core with a boost inductor. The inductance of the two snubber inductors are the same $\left(L_{2}=L_{3}\right)$, since they have the same turns ratio. However, the two inductors can no longer be considered as two individual inductors because of the coupling effect. The performance of the proposed lossless snubber circuit is strongly related to the direction of the windings. There are two similar equivalent circuits for each of the coupling formats during Mode 1, as shown in Fig. 4. The two snubber inductors can be directly coupled or inversely coupled due to the different direction selections between the two windings. In order to analyze the operation of the proposed snubber circuit through the difference in the direction of the windings, it is assumed that the coupling effect between the two inductors is perfectly coupled and that the input voltage of the snubber circuit is fixed by a constant voltage source $V_{i n}$.

Fig. 4(a) shows the recommended coupling methods. It has inverse coupled windings. When $S$ turns on during Mode 1, $D_{f}$ is not immediately turned off because of its reverse recovery characteristics. A momentary equivalent circuit of the proposed snubber circuit can express the simple circuit as shown in Fig. 4. During this period, the voltage across $L_{2}$ and $L_{3}$ is shown as follow:

$$
V_{\text {out }}=\left(L_{2} \frac{d I_{L 2}}{d t}+M \frac{d I_{L 3}}{d t}\right)+\left(L_{3} \frac{d I_{L 3}}{d t}+M \frac{d I_{L 2}}{d t}\right)
$$

where the coupling inductance $M=k \sqrt{L_{2} L_{3}}$, and $k$ is coupling coefficient. Since the inductance of $L_{l}$ is much greater than the inductance of $L_{2}, I_{L 2}$ should be much larger than $I_{L l}$. For this assumption, the switch current $I_{S}$ is approximately equal to $I_{L l}$. (22) can be substituted by (23).

$$
V_{\text {out }} \simeq\left(L_{e q}\right) \frac{d I_{L 2}\left(t_{0}\right)}{d t}
$$

where the equivalent inductance $L_{e q}$ using the inverse coupled winding can be defined by (24).

$$
L_{e q}=L_{2}+L_{3}+2 M
$$

Since the coupled inductors $L_{2}$ and $L_{3}$ have the same turn ratio, the voltage of the inductors is also the same. At this time, the snubber inductors $L_{2}$ and $L_{3}$ limit the rising rate of the switch current. Therefore, by using (23), the current of snubber inductors $I_{L 2}$ is can be derived in (25).

$$
\frac{d I_{L 2}\left(t_{0}\right)}{d t} \simeq \frac{V_{\text {out }}}{L_{e q}}
$$

If the coupling coefficient in the inverse coupled windings case is defined as $k=1$, the equivalent inductance $L_{e q}$ is four times larger than $L_{2}$.

In the case of Fig. 4(b), the equivalent inductance $L_{e q}$ using the directly coupled winding can be defined by (26).

$$
L_{e q}=L_{2}+L_{3}-2 M
$$

If the coupling coefficient in the directly coupled windings is defined as $k=1$, the equivalent inductance $L_{e q}$ is zero. These windings cannot limit the rising rate of the reverse recovery current. Therefore, the coupling method of Fig. 4(a) is suitable for the proposed lossless snubber circuit. 


\section{B. The Passive Resonant Component}

The inductance of the coupled $L_{2}$ and $L_{3}$ is determined by considering the variation of the output diode current in Mode 1. The current of the output diode equals the current of $L_{2}$ at $t_{0}$. Thus, the inductances of $L_{2}$ and $L_{3}$ are shown as:

$$
L_{2}=L_{3}=\frac{V_{\text {out }}}{2}\left(\left.\frac{d I_{L 2}(t)}{d t}\right|_{t=t_{0}}\right)^{-1} \simeq \frac{L_{e q}}{2}
$$

where $\frac{d I_{L 2}\left(t_{0}\right)}{d t} \simeq \frac{V_{\text {out }}}{L_{e q}}$. In order to reduce the current stress caused by the reverse recovery of the diode rectifier, the variation of $d I_{L 2}\left(t_{0}\right) / d t$ should be lower than $\frac{V_{o u t}}{L_{e q}} \leq 100 \times 10^{6} \quad[13]$. The snubber inductors $L_{2}$ and $L_{3}$ should be selected with respect to (28).

$$
L_{e q} \geq \frac{V_{\text {out }}}{100} \mu H
$$

The snubber capacitor $C_{x}$ is continuously charged by the energy from $C_{s}$ through $D_{s 2}$ in Mode 2. Since the energy in $C_{s}$ is completely transferred to $C_{x}$ in this period, the following condition can be obtained as shown in (29).

$$
V_{C x}\left(t_{2}\right) \geq V_{\text {out }} \sqrt{\frac{1}{\alpha}}
$$

where the voltage across $C_{s}$ is $V_{C s} \simeq V_{\text {out }}$ and the ratio between $C_{x}$ and $C_{s}$ is $\alpha=C_{x} / C_{s}$. The minimum voltage of $V_{C x}\left(t_{2}\right)$ is determined by the chosen value of $\alpha$. The energy stored in the coupled inductors of $L_{2}$ and $L_{3}$ is transferred to $C_{x}$ in Mode 3. The capacitance of $C_{x}$ can be designed as follows:

$$
C_{x} \geq \frac{L_{e q} I_{r r}{ }^{2}}{V_{C x}{ }^{2}\left(t_{3}\right)-V_{C x}{ }^{2}\left(t_{2}\right)}
$$

where $I_{r r}$ is the peak value of the reverse recovery current. The minimum capacitance of $C_{x}$ can be obtained from (30), and this design criteria guarantees the soft switching operation of power switch $\mathrm{S}$, which reduces the switching losses and improves power conversion efficiency of the proposed PFC circuit.

\section{POWER LOSS ANALYSIS}

In order to improve the power conversion efficiency, reducing the effects of the reverse-recovery characteristic is one of the most important research topics in high power CCM boost PFC applications. A fast recovery diode (FRD) has a small reverse recovery time $\left(t_{r r}\right)$. In the operation of the CCM boost PFC, $t_{r r}$ causes the reverse recovery current to increase additional power losses and EMC problems. These drawbacks can be minimized by employing $\mathrm{SiC}$ diodes or soft switching circuits instead of conventional diode rectifiers. In theory, the $\mathrm{SiC}$ diode has a very small $t_{r r}$. In addition, the $\mathrm{SiC}$ diode which has the simplest structure can reduce the power losses caused by the reverse recovery current. However, it still has a hard switching problem of the main

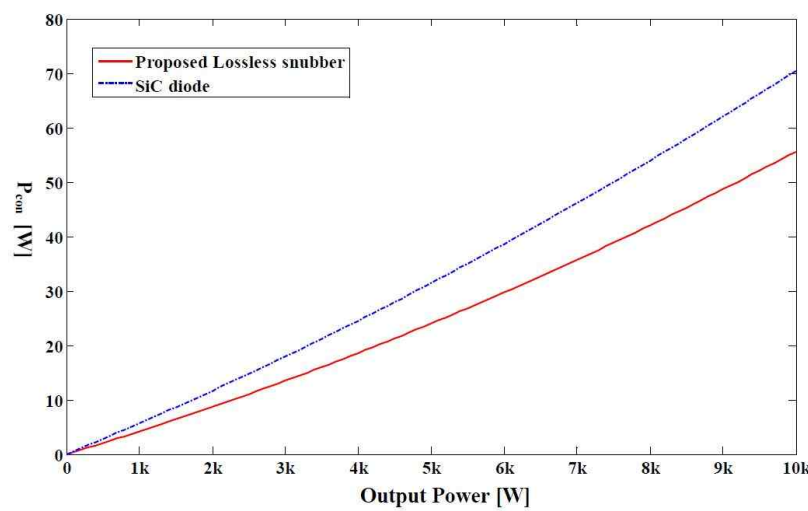

Fig. 5. Conduction loss of a main PFC switch and the boost rectifier diode according to the proposed lossless snubber and the $\mathrm{SiC}$ diode.

switch. Furthermore, the $\mathrm{SiC}$ diode has a higher forward voltage drop than that of the other conventional FRDs. If the output power increases, the power loss of the $\mathrm{SiC}$ diode is also increased.

In order to reduce these problems, a soft-switching technique with the couple inductor method has been proposed in this paper. Even though, it requires a relatively large number of passive or active components, the proposed technique in high power rectifier applications is a good solution for reducing the reverse recovery problems. In order to verify the usefulness of the proposed circuit, a detailed power loss analysis of the proposed CCM boost PFC will be discussed in the next subsections.

\section{A. Consideration of the Conduction Losses}

The major conduction losses in PFC rectifiers are caused by the three parts of the PFC's power stage; full-bridge rectifier diodes, a main $\mathrm{PFC}$ switch, and a boost rectifier diode. In order to analyze the conduction loss of the PFC rectifier, its circuit operation assumes that the boost inductor $L_{I}$ is sufficiently large to operate under the CCM and that the $\mathrm{AC}$ input current is perfectly sinusoidal. In this case, there is no difference in the conduction losses of the full-bridge rectifier diodes between the lossless snubber circuit and the $\mathrm{SiC}$ diode. However, the calculations of the conduction losses in the main PFC switch and the boost rectifier diode should consider the effects of the lossless snubber circuit and the $\mathrm{SiC}$ diodes.

Generally, the conduction loss in the main MOSFET can be calculated by using the rms current passing through its drain-source channel resistance, $R_{D S \text {.on. }}$ In addition, the conduction loss in the boost rectifier diode can be calculated by using the forward voltage drop of the boost diode, $V_{F}$. The rms current of the MOSFET can be calculated using the following equation:

$$
I_{r m s . s w}=\sqrt{\frac{1}{2 \pi} \int_{o}^{D_{a v} \times 2 \pi}\left(I_{i n . P} \sin \omega t\right)^{2} d \omega t}
$$


where the average turn-on period of the main PFC switch, $D_{a v}$, can be determined by as follows:

$$
D_{a v}=\frac{V_{\text {out }}-\sqrt{2} V_{\text {in.rms }}}{V_{\text {out }}}
$$

For this calculation, the peak current, $I_{i n . P}$ and the average current, $I_{\text {in.av }}$ of the AC input can be derived as follows:

$$
\begin{gathered}
I_{\text {in. } P}=\sqrt{2} \frac{P_{\text {out }}}{\eta V_{\text {in.rms }}} \\
I_{\text {in.av }}=\frac{2}{\pi} I_{\text {in. } P}
\end{gathered}
$$

where $\eta$ is the power conversion efficiency. Using (31) - (34), the conduction losses in the main PFC switch and boost rectifier diode can be calculated as follows:

$$
P_{c o n} \simeq I_{r m s . s w}^{2} R_{d s . o n}+\left(1-D_{a v}\right) I_{\text {in.av }} V_{F}
$$

where the conduction loss is $P_{c o n}$, and $V_{F}$ is the forward voltage drop of the boost rectifier diode. A MOSFET (IXKR47N60C5) is used for the main PFC switch with a low $R_{d s . o n}$ of $45 m \Omega$, a FRD DSEI2X101-06 is used for the boost rectifier diode with a low $V_{F}$, and a $\mathrm{SiC}$ diode (C3D20060D) manufactured by Cree is used for replacing the lossless snubber circuit and FRD. Since $R_{d s . o n}$ is the same in the case of the lossless snubber circuit and the $\mathrm{SiC}$ diode, $P_{c o n}$ is expected to be only affected by $V_{F}$. Fig. 5 shows the conduction losses of the PFC rectifier with the proposed lossless snubber and the $\mathrm{SiC}$ diode. Under the $10 \mathrm{~kW}$ load condition, the difference in the conduction losses between the lossless snubber circuit and the $\mathrm{SiC}$ diode in the $\mathrm{PFC}$ rectifier is $15 \mathrm{~W}$. Therefore, the PFC rectifier with the proposed lossless snubber circuit can increase the power conversion efficiency when compared with the case of the SiC diode in high power applications.

\section{B. Consideration of the Switching Losses}

The operating waveforms of the PFC rectifier for a single switching cycle are shown in Fig. 6. When the main PFC switch turns on, in the case of the FRD rectifier, the diode cannot immediately turn off because of its reverse recovery process during $t_{r r}$. This simultaneous high reverse recovery current causes an additional switching loss in the main PFC switch. In order to analyze this phenomenon, the reverse recovery characteristics of the FRD are illustrated in Fig. 6 (a). $I_{R R}$ is the maximum reverse current of the FRD. $t_{a}$ is the time duration between the zero crossing point and the peak point of the reverse current, which is related to the charge stored in the depletion region of the junction. $t_{b}$ is time duration of the charge stored in the bulk semiconductor material. $t_{r r}$ can be expressed as $t_{r r}=t_{a}+t_{b}$. In addition, the reverse recovery charge $Q_{R R}$ and the maximum reverse current $I_{R R}$ can be calculated as shown in (36) and (37).

$$
\begin{gathered}
Q_{R R}=\frac{1}{2} I_{R R} t_{a}+\frac{1}{2} I_{R R} t_{b}=\frac{1}{2} I_{R R} t_{r r} \\
I_{R R}=\frac{2 Q_{R R}}{t_{r r}}
\end{gathered}
$$

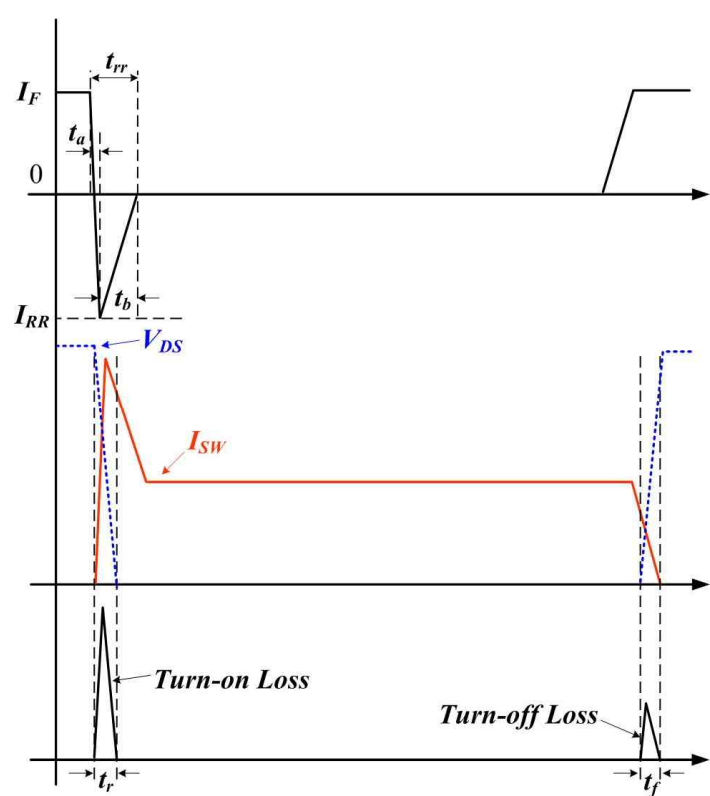

(a)

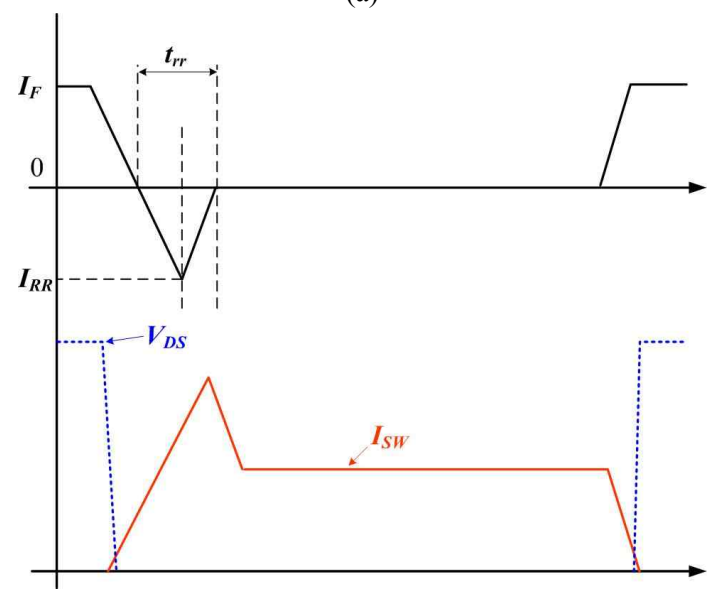

(b)

Fig. 6. The operating waveforms of the PFC rectifier for a single switching cycle. (a) FRD diode-based PFC, (b) The proposed lossless snubber PFC.

From (37), $I_{R R}$ is directly proportional to $Q_{R R}$. The values of $Q_{R R}$ and $t_{r r}$ are provided on the data sheet of the diode used in the rectifier.

A large $I_{R R}$ increases the current stress in the low side switches and decreases the EMI performance of the rectifier. If a $\mathrm{SiC}$ diode is used for the boost rectifier diode, $t_{r r}$ in the $\mathrm{SiC}$ diodes is theoretically zero and $I_{R R}$ should also be zero. Even though these values are not completely zero in practical operation, $I_{R R}$ is significantly reduced when comparing to the FRD operation. However, this method still has a hard switching problem in the main PFC switch. The average switching loss in the main PFC switch due to turn-on and turn-off transitions can be approximated as follows:

$$
\begin{gathered}
P_{s w-F R D} \simeq \frac{1}{2} f_{s w} V_{D S}\left[\left(I_{R R}+I_{\text {in.av }}\right) t_{r}+I_{\text {in.av }} t_{f}\right] \\
P_{s w-S i C} \simeq \frac{1}{2} f_{s w} V_{D S} I_{\text {in.av }}\left[t_{r}+t_{f}\right]
\end{gathered}
$$




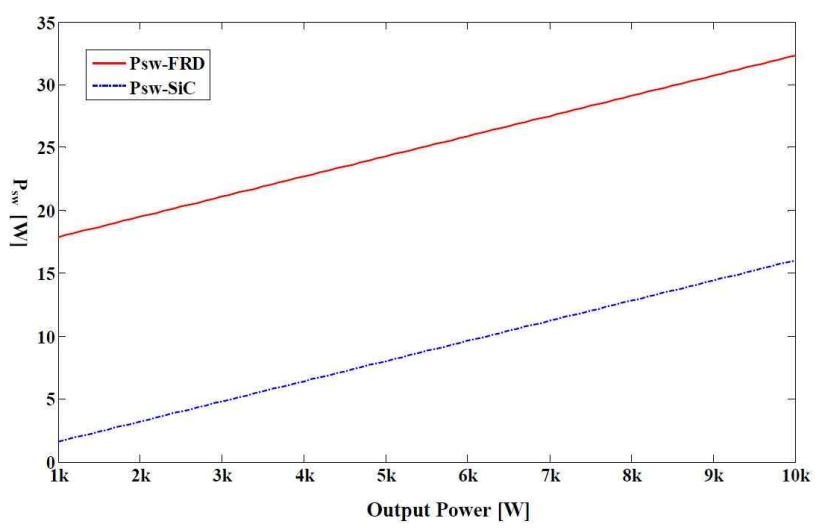

Fig. 7. Switching losses in the conventional FRD diode based PFC and $\mathrm{SiC}$ diode based PFC.

where the switching loss with the FRD is $P_{s w-F R D}$, the switching loss with the $\mathrm{SiC}$ is $P_{s w-S i C}$, and $f_{s w}$ is the switching frequency of the PFC rectifier. This shows that the switching loss in the main PFC switch changes linearly according to $f_{s w}$, $I_{R R}$, and $I_{\text {in.av }}$. Fig. 7 shows the calculated conduction losses using (38) and (39). The typical values of $t_{t}, t_{f}, Q_{R R}$, and $t_{r r}$ are obtained from the data-sheets provided by manufactures. From the results of Fig. 7, the switching losses of the PFC rectifier using the $\mathrm{SiC}$ diode are much smaller than those of the PFC rectifier using the FRD. However, the switching loss of the PFC rectifier using the $\mathrm{SiC}$ diode also increases according to the increment of the output power.

In order to increase the power conversion efficiency, a proposed lossless snubber circuit with the coupled inductor method is proposed in this paper. Fig. 6(b) shows the operating waveforms of the proposed lossless snubber PFC. When the main PFC switch turns on, the inductors of the proposed snubber limit the rising rate of the switch current. Therefore, current passing through the main PFC switch during the turn-on and turn-off intervals is reduced. The turn-on operation is similar to the mechanism of zero current switching and the turn-off operation is similar to the mechanism of zero voltage switching. Therefore, the switching loss during the turn-on and turn-off intervals will be dramatically reduced. The switching loss of the proposed PFC rectifier is negligible when compared to the cases of the conventional FRD diode and the $\mathrm{SiC}$ diode.

\section{EXPERIMENTAL RESULTS}

Fig. 8 shows a prototype converter of the proposed PFC boost rectifier. Table I shows the designed parameters of the proposed boost PFC converter. A $3.3 \mathrm{~kW}(380$ V/8.7A) PFC boost rectifier using the proposed lossless snubber has been designed and evaluated at $220 \mathrm{Vac}$ input voltage. The fixed switching frequency was $50 \mathrm{kHz}$ and the PFC rectifier power stage is operated in the CCM using a commercial controller (L4981) made by STmicroelectonics. The boost inductor is

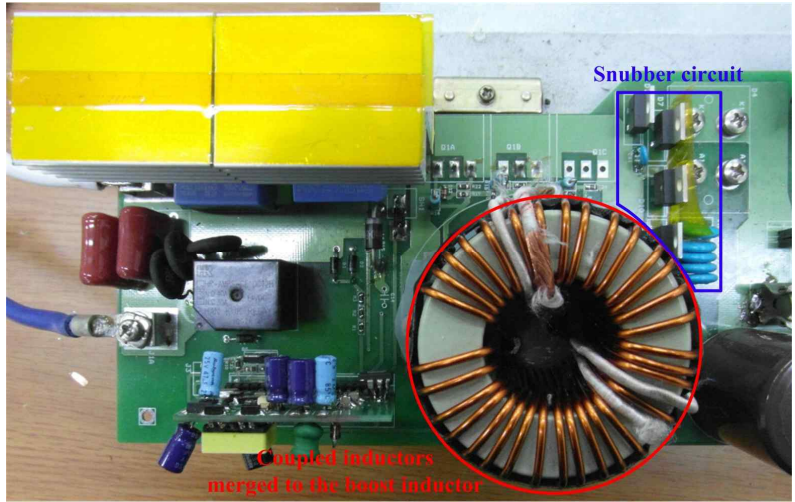

Fig. 8. Prototype circuit of the proposed PFC.

TABLE I

The Design Specifications of The Proposed Boost PFC CONVERTER

\begin{tabular}{lc}
\hline \multicolumn{1}{c}{ Specifications } & Values \\
\hline Input Voltage $\left(V_{\text {in }}\right)$ & AC $220 \mathrm{~V}$ \\
Output Voltage $\left(V_{\text {out }}\right)$ & DC $380 \mathrm{~V}$ \\
Rated Power $\left(P_{\text {out }}\right)$ & $3.3 \mathrm{~kW}$ \\
Control IC & L4981 \\
Main Switch $(S)$ & IXKR47N60C5 \\
Fast Recovery Didoe $\left(D_{f}\right)$ & DSEI12X101-06 \\
Snubber Diode $\left(D_{x}\right.$ and $\left.D_{s}\right)$ & MUR860 \\
Coupled Inductor turns ratio & $N 1: N 2: N 3=32: 2: 2$ \\
Boost Inductance & $L_{l}=800 \mu \mathrm{H}$ \\
Snubber Inductance & $L_{2}=L_{3}=3.6 \mu \mathrm{H}$ \\
Snubber Capacitance & $C_{s}=2.2 n F, C_{x}=130 \mathrm{nF}$ \\
Output Capacitance & $C_{o}=2 m F$ \\
\hline
\end{tabular}

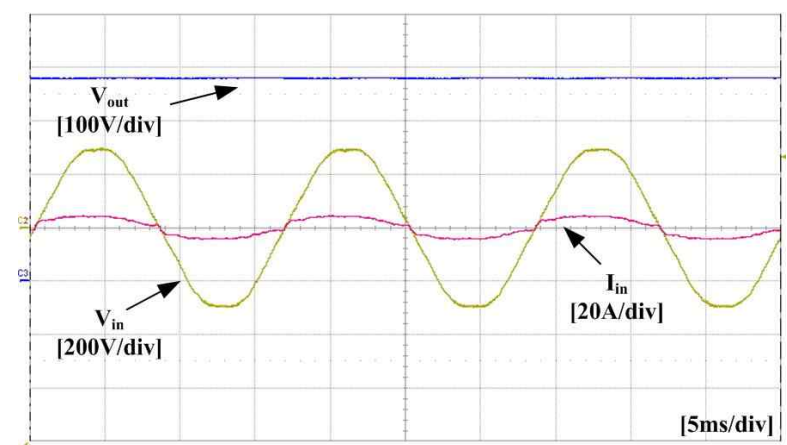

(a)

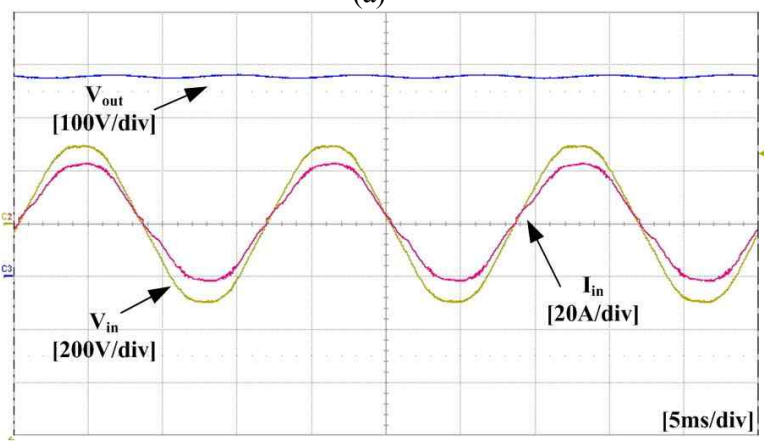

(b)

Fig. 9. The waveforms of the input voltage and current of the prototype PFC rectifier. (a) $660 \mathrm{~W}$ output power, (b) $3.3 \mathrm{~kW}$ rated output power. 
designed to $L_{1}=800 \mu \mathrm{H}$. The component values of the proposed snubber circuit are also given in Table I. In order to reduce the current stress caused by the reverse recovery characteristics, the coupled inductors are designed so that $L_{2}$ $=L_{3}=3.6 \mu \mathrm{H}$. The coupled inductors were implemented using a commercial toroidal core (CH610125, Chang-sung, two cores in parallel) with 32 turns for the boost inductor and 2 turns for each of the inductors. If the coupling coefficient in the inverse coupled windings case is defined to $k=1$, the equivalent inductance is $L_{e q}=14.4 \mu \mathrm{H}$. Based on (27), the variation value of the reverse recovery current is determined by $d I_{L 2}\left(t_{0}\right) / d t=26 \mathrm{~A} / \mu \mathrm{S}$. It is lower than the recommended value of $100 \mathrm{~A} / \mu \mathrm{S}$. The peak value of the limited reverse recovery current through the main switch, $I_{r r}$, has been designed with a $30 \%$ design margin of the rated current.

$$
I_{r r}=1.3 \times \sqrt{2} \times \frac{3300}{220}=27.6 \mathrm{~A}
$$

By setting $\alpha=50$ in (29) and $V_{C x}\left(t_{3}\right)=200 \mathrm{~V}$ in (30), the snubber capacitance $C_{x}$ is found to be $C_{x} \geq 125 n F$. Therefore, the practical values of $2.2 n F$ and $130 n F$ are selected for $C_{s}$ and $C_{x}$.

The measured waveforms of the input voltage and current are shown in Fig. 9 (a) and (b), respectively. Fig. 9 (a) shows the PFC operation of the prototype rectifier at $20 \%$ of the rated load condition. Fig. 9 (b) shows the input voltage and current waveforms under the rated load condition. In these figures, both the line voltage and current waveforms under a light load and a full load are almost in phase. From these results, the PFC operation of the prototype rectifier using the proposed lossless snubber is verified.

Fig. 10 (a) and (b) show the switching waveforms of the boost $\mathrm{PFC}$ rectifier using a $\mathrm{SiC}$ diode. Fig. 10 (a) shows the switch voltage and current during the turn-on transition. The current and voltage spikes are smaller than when using the conventional FRD diode since the SiC diode has a very small reverse recovery charge [23]. However, it still has a hard switching problem of the main switch. It also has switching losses during the turn-off transition as shown in Fig. 10 (b). If the rated power or the switching frequency increases, the power loss of the $\mathrm{SiC}$ diode is also increased.

If the FRD is used as a boost diode without snubber circuits, it makes a high current spike and a high voltage spike because of the high reverse recovery current from the FRD diode when it turns off. Fig. 11 (a) shows the voltage and current waveforms of the main switch during the turn-on transition. The experimental results verify that the variation of the output diode current is limited by the proposed turn-on lossless snubber using coupled inductors. When the main switch $S$ turns off, the reverse recovery current of the output diode is limited by the coupled inductors $L_{2}$ and $L_{3}$. Fig. 11 (b) shows the voltage and current waveforms of the main switch during the turn-off transition. The proposed turn-off lossless snubber $\left(C_{s}, D_{s 1}\right.$, and $\left.D_{s 2}\right)$ can reduce the voltage

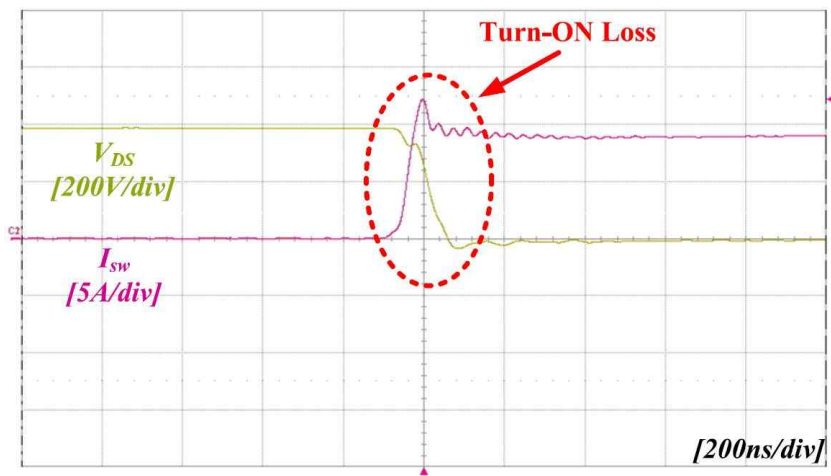

(a)

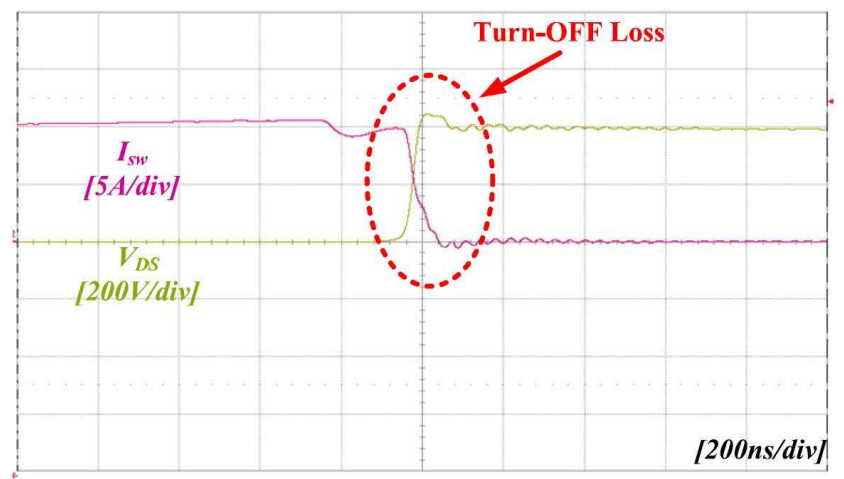

(b)

Fig. 10. Measured waveforms of the switch voltage and current using SiC diode under half load condition. (a) During turn-on transition, (b) During turn-off transition.

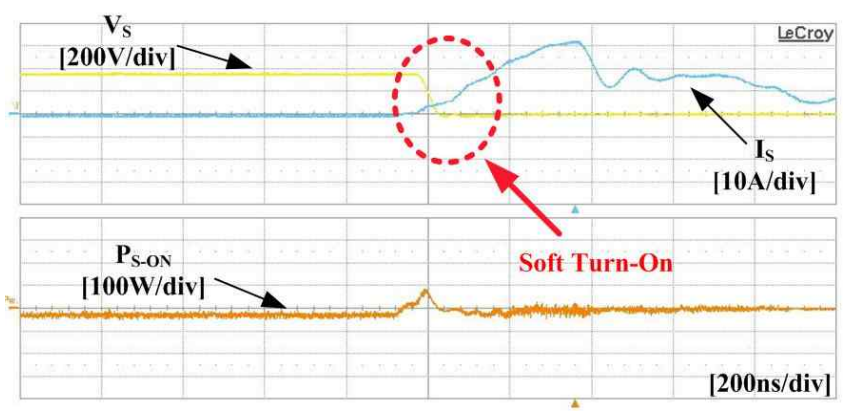

(a)

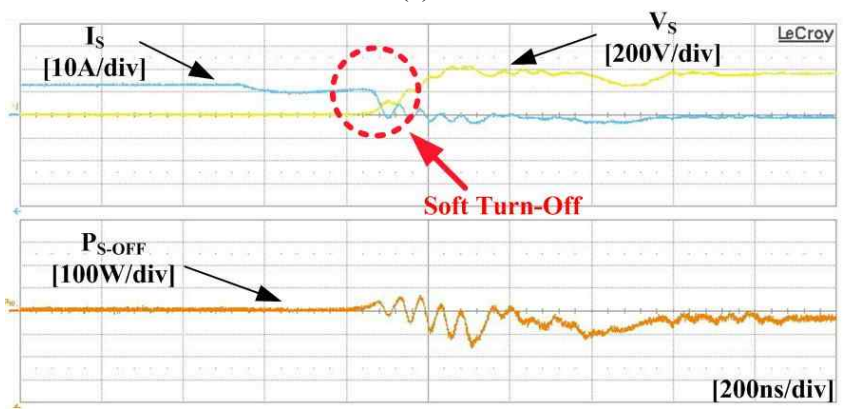

(b)

Fig. 11. Measured waveforms of the switch voltage and current using the proposed lossless snubber circuit under the rated load condition. (a) During turn-on transition. (b) During turn-off transition. 


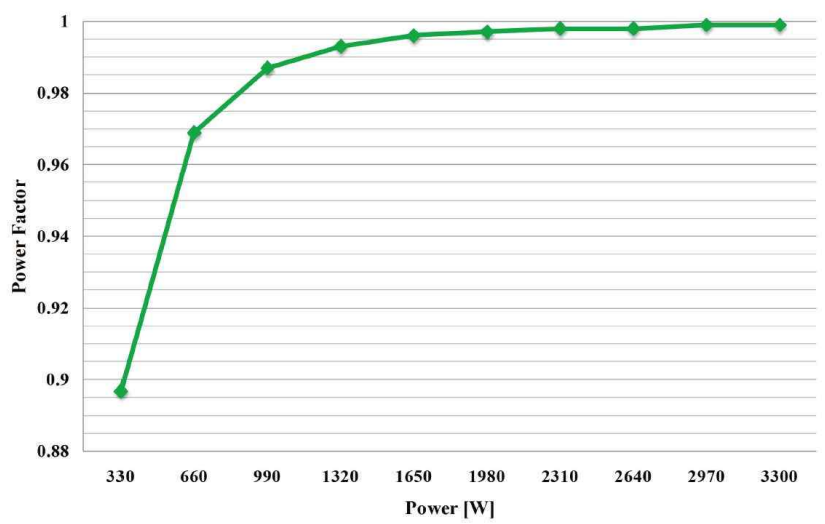

Fig. 12. Measured power factor of the prototype rectifier.

stresses across the main switch. The proposed lossless snubber does not introduce extra voltage and current stresses on the main switch during the turn-on and turn-off periods. It reduces the overlapped area between the voltage and current of the switch. The soft switching using the proposed lossless snubber can increase the power conversion efficiency of the $\mathrm{PFC}$ rectifier and reduce the heat emission from the switching MOSFETs.

Fig. 12 shows the measured curve of the power factor according to the output power. Above the $40 \%$ power region, the PFC rectifier can achieve an almost unity power factor. From the experimental results, the PFC operation of the proposed prototype rectifier shows good performance under output load variations.

Fig. 13 shows the efficiency curve of the CCM PFC boost rectifier using the proposed lossless snubber. It is measured at an input voltage of $220 \mathrm{Vac}$. In order to compare the power conversion efficiency, a commercial SiC diode (CS320060D) was used for the rectifier diode of the boost PFC rectifier. From the experimental results, it can be seen that the efficiency of the rectifier with the $\mathrm{SiC}$ diode is slightly higher than the efficiency of the proposed lossless snubber method under $40 \%$ of the rated load. The experimental results in Fig. 13 are slightly different from the calculation of the conduction loss in Fig. 7 because of neglecting the switching loss of the proposed PFC rectifier. However, at over $40 \%$ of the rated load, the power conversion efficiency of the FRD-based rectifier with the proposed lossless snubber circuit is higher than that of the $\mathrm{SiC}$ diode based rectifier. The increasing power losses of the $\mathrm{SiC}$ diode based rectifier are a hard switching problem of the main switch and the conduction losses of the $\mathrm{SiC}$ diode. The conduction loss of the rectifier diode depends on the forward voltage drop of the $\mathrm{SiC}$ diodes. The $\mathrm{SiC}$ diode (C3D20060D) has a higher forward voltage drop $\left(V_{f}=1.5\right)$ than that of the FRD DSEI2X101-06 $\left(V_{f}=1.17\right)$. At the rated load of $3.3 \mathrm{~kW}$, the difference in the conduction losses between the lossless snubber circuit and the $\mathrm{SiC}$ diode in the PFC rectifier is $5 \mathrm{~W}$. Fig. 14 shows calculated power loss graphs at the rated load

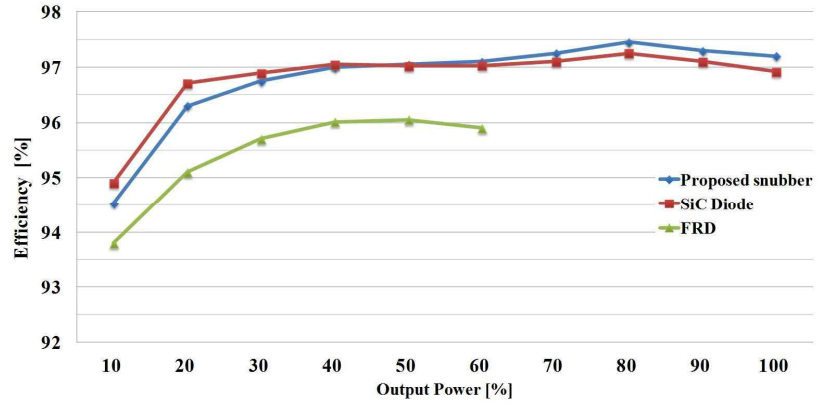

Fig. 13. Measured efficiency of the prototype rectifier.

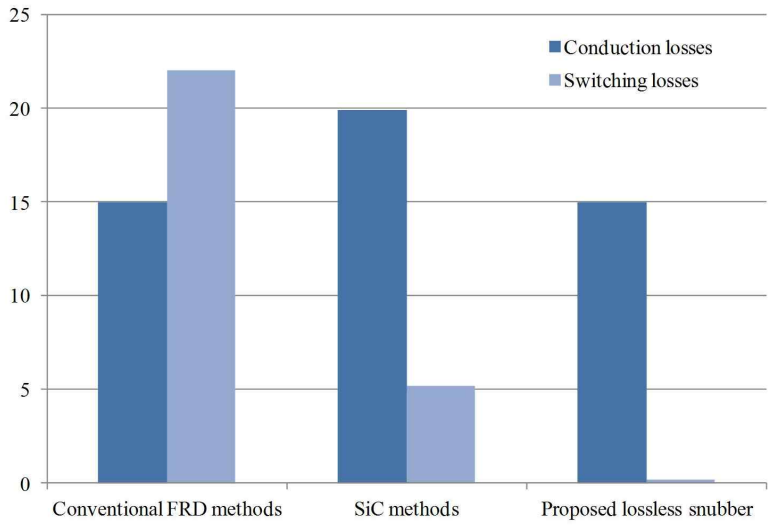

Fig. 14. Power loss graph under the rated load condition.

condition using (35), (38), and (39). As shown in Fig. 14, the switching losses of the conventional PFC rectifier using the FRD without snubber circuits is significantly increased. In addition, the proposed lossless snubber circuit can reduce more power loses than the $\mathrm{SiC}$ diode in this condition. The power conversion efficiency of the conventional PFC method is decreased by about $1.2 \%$ at $60 \%$ of the rated load when compared to the proposed methods. The power conversion efficiency of the proposed rectifier is higher than $97 \%$ when the output power is above $40 \%$ of the rated load. The highest efficiency is $97.48 \%$ at $2.64 \mathrm{~kW}$. At the rated output power of $3.3 \mathrm{~kW}$, the power conversion efficiency is $97.2 \%$.

\section{CONCLUSIONS}

In this paper, the detailed performance improvement and the analysis of the operating effects of the coupled inductors were presented. In order to verify the improvement of the proposed snubber circuit, a $3.3 \mathrm{~kW}$ prototype $\mathrm{PFC}$ rectifier using a commercial PFC controller was designed. The power conversion efficiency of the proposed circuit increases around $1.2 \%$ at $60 \%$ compared with the conventional methods. The power conversion efficiency of the proposed rectifier is higher than $97 \%$ when the output power is above $40 \%$ of the rated load. Even though the proposed technique requires a relatively large number of passive or active components, it is a good solution for high power rectifier applications by reducing the reverse recovery problems. 


\section{ACKNOWLEDGEMENT}

This research was supported by the KERI Primary research program of MSIP/ISTK (No. 15-12-N0101-04).

\section{REFERENCES}

[1] D. D. C. Lu, H. H. C. Iu, and V. Pjevalica, "A single-stage $\mathrm{AC} / \mathrm{DC}$ converter with high power factor, regulated bus voltage, and output voltage," IEEE Trans. Power Electron., Vol. 23, No. 1, pp. 218-228, Jan. 2008.

[2] J. Y. L. Huber and M. M. Jovanovic, "Performance evaluation of bridgeless PFC boost rectifiers," IEEE Trans. Power Electron., Vol. 23, No. 3, pp. 1381-1390, May 2008.

[3] D. D. C. Lu, H. H. C. Iu, and V. Pjevalica, "Single-stage AC/DC boost: Forward converter with high power factor and regulated bus and output voltages," IEEE Trans. Ind. Electron., Vol. 56, No. 6, pp. 2128-2132, Jun. 2009.

[4] E. L. Huber, B. T. Irving, and M. M. Jovanovic, "Effect of valley switching and switching-frequency limitation on line-current distortions of DCM/CCM boundary boost pfc converters," IEEE Trans. Power Electron., Vol. 24, No. 2, pp. 339-347, Feb. 2009.

[5] Y. Fei, R. Xinbo, Y. Yang, and Y. Zhihong, "Interleaved critical current mode boost PFC converter with coupled inductor," IEEE Trans. Power Electron., Vol. 26, No. 9, pp. 2404-2413, Sep. 2011.

[6] G. Spiazzi, S. Buso, M. Citron, M. Corradin, and P. Roberto, "Performance evaluation of a schottky sic power diode in a boost PFC application," IET Power Electron., Vol. 18, No. 6, pp. 1249-1253, Nov. 2003.

[7] L. Lorenz, G. Deboy, and I. Zverev, "Matched pair of coolmos transistor with SiC-Schottky diode advantages in application," IEEE Trans. Ind. Appl., Vol. 40, No. 5, pp. 1265-1272, Sep./Oct. 2004.

[8] H. Bai, A. Taylor, W. Guo, G. Szatmari-Voicu, N. Wang, J. Patterson, and J. Kane, "Design of an $11 \mathrm{~kW}$ power factor correction and $10 \mathrm{~kW}$ ZVS de/dc converter for a high-efficiency battery charger in electric vehicles," IET Power Electron., Vol. 5, No. 9, pp. 1714-1722, Nov. 2012.

[9] X. Liu, D. Xu, C. Hu, H. Yue, Y. Li, P. Lin, and H. Pan, "A highefficiency single-phase AC/DC converter with enabling window control and active input bridge," IEEE Trans. Power Electron., Vol. 27, No. 6, pp. 2912-2924, Jun. 2012.

[10] C.-J. Tseng and C.-L. Chen, "Passive lossless snubbers for DC/DC converters," in APEC'98. Conference Proceedings, pp. 1049-1054, 1998.

[11] M. M. Jovanovic and Y. Jang, "A novel active snubber for high power boost converter," IEEE Trans. Power Electron., Vol. 15, No. 2, pp. 278-284, Mar. 2000.

[12] K. M. J. Smith and K. M. Smedley, "Engineering design of lossless passive soft switching methods for PWM converters. ii. Nonminimum voltage stress circuit cells," IEEE Trans. Power Electron., Vol. 17, No. 6, pp. 864-873, Nov. 2002.

[13] M. M. Jovanovic and Y. Jang, "State-of-the-art, single-phase, active power-factor-correction techniques for high-power applications - An overview," IEEE Trans. Ind. Electron., Vol. 52, No. 3, pp. 701-708, Jun. 2005.

[14] B. Irving and M. Jovanovic, "Analysis, design, and performance evaluation of flying-capacitor passive lossless snubber applied to PFC boost converter," in APEC'2002. Conference Proceedings, pp. 503-508, 2002.

[15] M. Mahesh and A. Panda, "A high performance single-phase AC-DC PFC boost converter with passive snubber circuit," in ECCE'2012. Conference Proceedings, pp. 2888-2894, 2012.

[16] H. Wu and X. He, "Single phase three-level power factor correction circuit with passive lossless snubber," IEEE Trans. Power Electron., Vol. 17, No. 6, pp. 946-953, Nov. 2002.

[17] S. gong Jiang, G. hua Liu, W. Wang, and D. guo Xu, "Research on bridgeless boost PFC with soft-swithching," in 2009 IEEE Vehicle Power and Propulsion Conference, pp. 1461-1464, 2009.

[18] K. I. Hwu, C.-L. Tsai, and K.-F. Lin, "A simple passive ZCS circuit for PFC converter," in IEEE 2008 Applied Power Electronics Conference, pp. 1022-1026, 2008.

[19] K. Schenk, "Non dissipative snubber circuit with saturable reactor," in U.S. Patent 7233 507, Jun. 2008.

[20] G. Joung, K. Ma, and Y. Kim, "Battery discharger applications of high frequency boost converter with lossless snubber," in Proc. 33th IEEE Power Electron. Spec. Conf. (PESC), pp. 938-942, 2002.

[21] R. T. H. Li, H. S.-H. Chung, and A. K. T. Sung, "Passive lossless snubber for boost PFC with minimum voltage and current stress," IEEE Trans. Power Electron., Vol. 25, No. 3, pp. 602-613, Mar. 2010.

[22] H.-S. Kim, J.-W. Baek, J.-H. Jung, J.-H. Kim, M.-H. Ryu, and H.-J. Kim, "A boost PFC rectifier with a passive lossless snubber circuit using coupled inductors methods," in APEC'2012. Conference Proceedings, pp. 1148-1152 2012.

[23] H.-S. Kim, M.-H. Ryu, J.-W. Baek, and J.-H. Jung, "High-efficiency isolated bidirectional AC-DC converter for a DC distribution system," IEEE Trans. Power Electron., Vol. 28, No. 4, pp. 1642-1654, Apr. 2013.

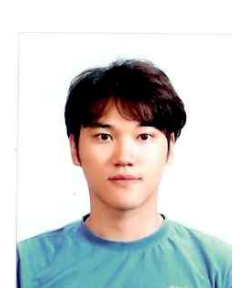

Ho-Sung Kim received his B.S., M.S., and Ph.D. degrees in Electrical Engineering from Pusan National University, Busan, Korea, in 2007, 2009, and 2013, respectively. Since 2007, he has been working as a Senior Researcher in the Power Conversion and Control Research Center, HVDC Research Division of the Korea Electro-technology Research Institute (KERI), Changwon, Korea. His current research interests include high power density DC/DC converters, high efficiency bidirectional AC-DC rectifier systems for low voltage DC distribution, high efficiency power factor correction circuits, and power converters for solid state transformers. Dr. Kim is a Member of the IEEE Industrial Electronics Society and the Korean Institute of Power Electronics (KIPE).

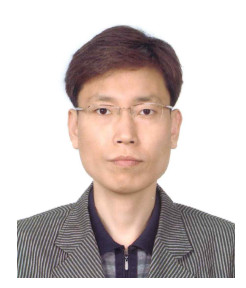

Ju-Won Baek received his M.S. and Ph.D. degrees from Kyungpook National University, Taegu, Korea, in 1993 and 2002, respectively. Since 1993, he has been working as a Principle Researcher in the Power Conversion and Control Research center, HVDC Research Division, KERI, Changwon, Korea. He was a Visiting Scholar at the Future Energy Challenge Center, Virginia Tech, Blacksburg, VA, USA, in 2004. His current research interests include soft-switching converters, power quality, high-voltage power supplies, and power converters for renewable energy. Recently, he has been working on a dc distribution system for a data center and a building to improve energy efficiency. Dr. Baek is a member of the KIPE and the IEEE Power Electronics Society. 


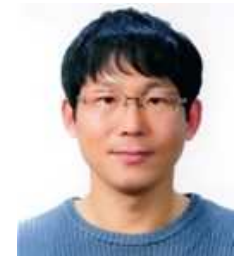

Myung-Hyo Ryu received his B.S. and M.S. degrees in Electrical Engineering from Kyungpook National University, Taegu, Korea, in 1997 and 1999, respectively. From 2000 to 2002, he was a Research Engineer with the SMPS Development Division, Samsung Electro-Mechanics Co. Ltd., Suwon, Korea. Since 2002, he has been a Senior Researcher with the Power Conversion and Control Research Center, HVDC Research Division, KERI, Changwon, Korea. His current research interests include LEDs drivers, power converters for low voltage DC distribution systems and high voltage DC transmission systems, and the analysis, modeling, design, and control of battery chargers. Mr. Ryu is a Member of the KIPE.

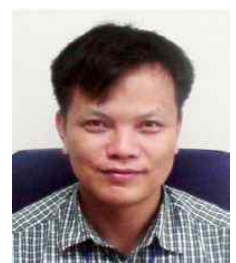

Jong-Hyun Kim received his M.S. and $\mathrm{Ph} . \mathrm{D}$. degrees from the Department of Electronic and Electrical Engineering, Pohang University of Science and Technology (POSTECH), Pohang, Korea, in 1994 and 1998, respectively. From 1998 to 2002, he was a Principal Research Engineer with the SMPS Development Division, Samsung Electro-Mechanics Co. Ltd., Suwon, Korea. Since 2002 , he has been a Principal Researcher with the Power Conversion and Control Research Center, HVDC Research Division, KERI, Changwon, Korea. His current research interests include AC direct LED drivers, power converters for high voltage DC transmission systems and the analysis, modeling, design, and control of special power applications.

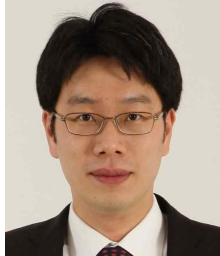

Jee-Hoon Jung was born in Suwon, Korea, in 1977. He received his B.S., M.S., and $\mathrm{Ph} . \mathrm{D}$. degrees from the Department of Electronic and Electrical Engineering, POSTECH, Pohang, Korea, in 2000, 2002, and 2006, respectively. He was a Senior

Research Engineer at the Digital Printing Division of Samsung Electronics Co., Ltd., Suwon, Korea, from 2006 to 2009. He was also a Postdoctoral Research Associate in the Department of Electrical and Computer Engineering, Texas A\&M University of Qatar (TAMUQ), Doha, Qatar, from 2009 to 2010. From 2011 to 2012, he was a Senior Researcher at the Power Conversion and Control Research Center, HVDC Research Division, KERI, Changwon, Korea. Since 2013, he has been an Assistant Professor in School of Electrical and Computer Engineering, Ulsan National Institute of Science and Technology (UNIST), Ulsan, Korea. His current research interests include $\mathrm{dc}-\mathrm{dc}$ converters, switched mode power supplies, motor drives and diagnosis systems, digital control and signal processing algorithms, digitally controlled power electronics, power conversion for renewable energy, and real-time and power hardware-in-the-loop simulations (HILS) of renewable energy sources. Recently, he has been researching very high-frequency power converters for consumer electronics, smart power transformers for smart grids, and wireless power transfer techniques for electric vehicle (EV) applications. Professor Jung is a Senior Member of the IEEE Industrial Electronics Society, the IEEE Power Electronics Society, the IEEE Industry Applications Society. He is also a Member of the Editor Committee of the KIPE and an Associate Editor of Journal of Power Electronics (JPE). 